\title{
ANALISIS KUALITAS PELAYANAN FRONTLINER PADA NASABAH PT BANK BNI SYARIAH KC PANORAMA BENGKULU
}

\author{
Oleh: \\ Tri Rahayu, Yanto, Indria \\ Program Studi Ilmu Komunikasi Fakultas Ilmu-Ilmu Sosial \\ Universitas Dehasen Bengkulu
}

\begin{abstract}
This study aims to find out how the frontliner services for customers of PT Bank BNI Syariah KC Panorama Bengkulu. This research is a descriptive study with a qualitative approach. Descriptive qualitative research aims to explain the phenomena as deeply as possible that occur in the field and present data systematically, factually, and accurately regarding the facts or phenomena that occur in the field. Data collection is done by means of initial observation, interviews and documentation. Data analysis in this study uses three components, namely data reduction, data presentation and conclusion. The results showed that the quality of service of PTBank BNI Syariah KC Panorama Bengkulu has implemented five dimensions of service quality according to Parasuarman et al, namely Tangible, Reliability,Responsivity, Assurance and Emphaty, but there are some things that have not gone according to customer wishes such as the inability of waiting room at PT Bank BNI Syariah KC Panorama Bengkulu, where the waiting room is too small, sometimes busy customers have to wait outside, then the lack of seats waiting sometimes customers waiting to stand up remember the condition of small and narrow room and for EDC tools that have to swipe cards repeatedly because the EDC engine is error.
\end{abstract}

\section{Keywords: Panorama BNI Customer, customer, service quality}

\section{PENDAHULUAN}

Perbankan sangat penting dalam perekonomian masyarakat, yang mana mampu memberikan kemudahan dan kelancaran dalam bidang ekonomi terutama di indonesia. Menurut Kasmir (2010:14) Bank adalah badan usaha yang menghimpun dana dari masyarakat dalam bentuk simpanan dan menyalurkannya kembali kepada masyarakat dalam bentuk kredit atau bentuk-bentuk lainnya dalam rangka meningkatkan taraf hidup rakyat banyak. Masyarakat menginginkan produk dan layanan berkualitas yang sesuai dengan kebutuhan mereka. Dalam sebuah organisasi atau perusahaan dituntut untuk mampu memberikan pelayanan yang baik dan berkualitas yang dapat memenuhi keinginan pelanggan atau nasabah, produk dan jasa serta pelayanan yang tidak memenuhi keinginan pelanggan atau nasabah dengan sangat mudah ditinggalkan dan pada akhirnya nasabah berpindah kepada perusahaan atau bank lain. Dengan demikian sebuah organisasi atau perusahaan akan mengutamakan pelayanan pada nasabah. Komunikasi adalah proses dimana suatu ide dialihkan dari sumber kepada suatu penerima atau lebih, dengan maksud untuk mengubah tingkah laku mereka Dalam bukunya Rohim (2009:21). Untuk menyampaikan keinginan dan hasratnya kepada orang lain manusia akan melakukan komunikasi yang baik entah secara lisan (verbal), melalui 
lambang-lambang isyarat (nonverbal) maupun tulisan.

Terjalinnya komunikasi yang baik antara Frontliner dan nasabah dapat meningkatkan nilai plus sebuah bank serta memberikan kemajuan bagi perusahaan, tantangan yang paling serius karena keberhasilan untuk mencapai tujuan dan kelangsungan hidup perusahaan tergantung pada kualitas pelayanan didalamnya. Kepuasan nasabah dalam sebuah organisasi atau perusahaan mempengaruhi tingginya peminat nasabah terhadap suatu perbankan. PT Bank BNI Syariah KC Panorama Bengkulu merupakan perusahaan perbankan yang bergerak di bidang jasa, yang mengutamakan pelayanan untuk kebutuhan nasabah agar perusahaan memiliki bagian terpenting dalam masyarakat, mengingat banyaknya perbankan yang bersaing ketat dalam mempromosikan banknya. dalam sebuah perbankan terdapat bagian khusus untuk untuk melakukan pelayanan terhadap nasabah, yaitu Frontliner merupakan garis terdepan perusahaan untuk membentuk citra yang baik dalam sebuah perusahaan dengan memberikan pelayanan yang terbaik kepada nasabah, oleh Karena itu kemampuan berkomunikasi harus dimiliki oleh frontliner dalam menjalankan tugas dan fungsinya. frontliner terdiri dari customer service, teller dan security. Adanya persaingan di dunia perbankan yang semakin ketat membuat perbankan semakin memberikan kualitas pelayanan yang terbaik, tentunya sesuai dengan aturan yang ada disebuah perusahaan itu sendiri, kualitas pelayanan yang diberikan oleh petugas fronyliner tak lepas dari nasabah, karena nasabah lah yang merasakan pelayanan yang diberikan, berdasarkan hasil observasi yang dilakukan banyaknya nasabah yang mengeluh terkait dengan antrian yang lama, kemudian ruang tunggu yang kecil dan tidak nyaman dan lamanya waktu transaksi. Berdasarkan hasil observasi peneliti di beberapa bank bahwasanya nasabah mengeluhkan hal-hal semacam itu, dari keluhan nasabah tersebut peneliti tertarik untuk menganalisis bagaimana kulitas pelayanan yang diberikan pihak frontliner khususnya frontliner di PT Bank BNI Syariah.

\section{METODE PENELITIAN}

Metode penelitian menggunakan pendekatan deskriptif kualitatif. Dalam penelitian kualitatif bertujuan untuk menjelaskan fenomena dengan sedalam dalamnya. Penelitian deskriptif kualitatif di tujukan untuk mengumpulkan

informasi secara rinci yang menggambarkan keadaan yang ada, mengidentifikasi masalah atau memeriksa kondisi dan praktik yang berlaku, mengumpulkan dan menuangkan data dari lapangan melalui observasi, wawancara dan dokumentasi untuk kemudian di analisis. Penelitian ini di awali dengan observasi awal yang dilakukan, kemudian melakukan wawancara terhadap pihak bank serta nasabah dan dokumentasi di PT Bank BNI Syariah KC Panorama Bengkulu.

\section{Sumber Data}

Data Primer adalah data yang diperoleh secara langsung dari sumber peneliti yakni dari sumber asli (tidak melalui perantara) yang secara khusus dikumpulkan oleh peneliti untuk menjawab pertanyaan penelitian. Dalam hal ini peneliti melakukan wawancara dengan pihak Operasional PT Bank BNI Syariah.

Data sekunder adalah sumber data penelitian yang diperoleh secara tidak langsung melalui perantara, umumnya berupa bukti atau catatan-catatan. Dalam hal ini peneliti memperoleh data dari dokumen - dokumen bank, buku juklak bank dan dokumentasi pribadi milik bank.

\section{Teknik Pengumpulan Data}


Teknik pengumpulan data yang dilakukan yaitu dengan wawancara, observasi dan dokumentasi.

\section{Teknik Analisa Data}

Dalam hal ini analisis data kualitatif, bogdan dalam sugiyonno (2014:88) menyatakan bahwa analisis data adalah suatu proses mencari dan menyusun sistem secara sistematis data yang diperoleh dari hasil wawancara, catatan lapangan dan bahan-bahan lain sehingga mudah dipahami dan semuanya dapat di informasikan kepada orang lain.

\section{HASIL PENELITIAN DAN PEMBAHASAN}

Untuk mengetahui kualitas pelayanan di PT Bank BNI Syariah saat ini, peneliti menggunakan lima dimensi kualitas pelayanan yang dikemukakan oleh Parasuarman Et Al yaitu Tangible (bukti fisik), Reliability (Kehandalan), Responsiviness (Ketanggapan), Assurance (Jaminan), dan Emphaty (Empati)

\section{Tangible (Bukti Fisik)}

Berdasarkan hasil observasi awal yang telah saya lakukan Di PT Bank BNI Syariah Panorama bahwa Frontliner telah menggunakan seragam lengkap dengan atributnya dan fasilitas yang nampak lainnya seperti papan nisbah, name desk, bunga, dan alat bantu dalam pelayanan pun digunakan Dari hasil wawancara diatas dapat diketahui bahwa penggunaan alat bantu dalam melakukan pelayanan itu sangat penting yang mana dapat mempermudah dan mempercepat kinerja kita sebagai petugas pelayanan, walaupun belum semua petugas memiliki alat bantu dalam pelayanan seperti alat cetak nomor antrian untuk nasabah

\section{Reliability (kehandalan)}

Berdasarkan hasil wawancara, dapat diketahui bahwa Frontliner PT Bank BNI Syariah memiliki kertas kerja khusus dalam melakukan pelayanan, yang mana setiap petugas frontlinernya memilik aturan tersendiri dalam melayani, nasabah kemudian dalam melakukam pelayanan ternyata ketelitian dan kecermatan amat sangat penting agar meminimalisir kesalahan.

\section{Responsiveness (daya tanggap)}

Ketika peneliti melakukan observasi awal hal yang dilakukan petugas begitu sigap dalam menanggapi nasabah, terlebih ketika nasabah mengalami kesulitan dalam pengisisan form yang disediakan untuk melakukan penarikan, berdasarkan hasil wawancara diatas diketahui bahwa setiap frontliner memiliki cara tersendiri untuk mengatasi keluhan nasabah, yang mana tetap pada prosedur yang sudah ditetapkan oleh kertas kerja PT Bank BNI Syariah.

\section{Assurance ( jaminan)}

Dari hasil observasi awal yang dilakukan untuk menumbuhkan rasa aman pada nasabah itu sendiri frontliner sebisa mungkin meyakinkan nasabah terkait produk, keamanan dalam Saving Dana dan keamanan dalam bertransaksi diperjelas dengan hasil wawancara diatas dapat kita ketahui bahwa di PT Bank BNI Syariah menjamin keamanan dana nasabah yang tersimpan. Sebuah lembaga yang menjamin dana nasabah tersebut yaitu LPS (Lembaga Penjamin Sosial), jadi nasabah yang sudah ataupun belum bergabung tak perlu khawatir. bukan hanya itu saja, agar nasabah bisa percaya dan loyal terhadap bank dipengaruhi juga oleh sikap dan pelayanan dari frontlinernya yang mana dapat membina hubungan yang baik dengan nasabah.

\section{Empati}

Ketika peneliti melakukan
observasi awal petugas $r$ belum
menampakkan sikap empati terhadap
nasabah, namun ketika melakukan
penelitian benar adanya bahwa dari hasil
wawancara dapat kita ketahui bahwa


petugas Frontliner PT Bank BNI Syariah mengutamakan kepentingan nasabah yang mana mereka mengedepankan urusan nasabah dibandingkan dengan urusan pribadi dan mengedepankan pelayanan yang terbaik dengan memberikan kepedulian dan perhatian pada nasabah.

\section{PENUTUP}

\section{Kesimpulan}

Adapun hasil yang dapat penulis simpulkan dalam penulisan ini yaitu:

1. Tangible (Bukti Fisik)

Penampilan petugas frontliner PT Bank BNI Syariah menggunakan seragam dan berpenampilan menarik, kemudian untuk penggunaan alat bantu dalam layanan yaitu mesin hitung, mesin EDC, lampu UV dan kamera logitech. Namun ada beberapa hal yang harus diperhatiakn yaitu keluasan area banking hall dan jumlah kursi untuk nasabah menunggu.

2. Reliability (Kehandalan)

Dalam hal ini memiliki sikap sopan santun, ramah, antusias dan memiliki kecakapan dalam hal Cross Selling dan Building Relationship yang mana keduanya memiliki kepandaian dalam komunikasi.

3. Responsiviness (Ketanggapan)

Ketika nasabah mengalami kesulitan atau terjadi permasalahan, petugas frontliner dengan sigap dan cepat dalam mengambil keputusan dalam menyelesaikan keluhan nasabah.

4. Assurance (Jaminan)

Memberikan rasa aman dan nyaman ketika berhubungan langusung dengan Bank. PT Bank BNI Syariah sudah terdapat lembaga yang mana menjamin simpanan nasabah, jadi nasabah tak perlu khawatir untuk saving dana di Bank BNI Syariah, kemudian untuk keamanan dan kerahasian data ketika bertransaksi petugas selalu mengkonfirmasi kebenaran dalam bertransaksi.

5. Empati
Memberikan perhatian khusus pada nasabah seperti ketika melakukan transaksi diluar jam layanan dan lebih mementingkan urusan nasabah daripada urusan pribadi.

\section{Saran}

Adapun saran yang dapat di kemukakan dalam penelitian ini adalah sebagai berikut ;

1. Kondisi ruangan Banking Hall PT Bank BNI Syariah lebih diperluas, karena nasabah yang cukup banyak.

2. Waktu tunggu pengembalian uang nasabah yang tertelan di ATM lebih dipersingkat kembali.

\section{DAFTAR PUSTAKA}

Bungin, Burhan. 2014. Penelitian Kualitatif. Jakarta : Kencana.

Creswell, John W, 2010. Penerjemah Achmad Fawaid. Research Design:

Pendekatan Kualitatif, Pendekatan Kuatitatif Dan Mixed.

Yogyakarta.Pustaka Pelajar

Dendawijaya, Lukman. 2003. Manajemen Perbankan. Jakarta : Ghalia Indonesia.

Idrus, Muhammad. 2009. Metode Penelitian Ilmu Sosial. Jakarta : Erlangga.

Irawan, Handi. 2002. 10 Prinsip Kepuasan Pelanggan. Jakarta : Pt Elex Media.

Kasmir. 2010. Bank \& Lembaga Keungan Lainnya. Jakarta : Pt Raja Grafindo

Kasmir. 2006. Manajemen Perbankan. Jakarta : Pt Raja Grafindo. 